International Journal of Child, Youth and Family Studies (2013) 3.1: 489-501

\title{
SPEAKING RIGHTS: YOUTH EMPOWERMENT THROUGH A PARTICIPATORY APPROACH
}

\section{Amy Cooper, Vincenza Nazzari, Julie Kon Kam King, and Annie Pettigrew}

\begin{abstract}
Using Equitas’ Speaking Rights Program as a best practice example, this article outlines the essential practices and conditions of a participatory approach to human rights education for youth, and explores how this approach effectively supports youth empowerment. The authors maintain that programs that use a participatory approach to human rights education are more likely to engage youth in actions for social change within their communities. They suggest that youth workers who are trained and well equipped to address issues that are on the minds of youth are critical in helping youth develop the skills and motivation to participate.
\end{abstract}

Keywords: youth empowerment, participatory approach, human rights education, sustainability

Amy Cooper (the corresponding author) is an Education Specialist at Equitas - International Centre for Human Rights Education, 666 Sherbrooke St. West, \#1100, Montréal, Québec, H3A 1E7. Telephone: (514) 621-4645, extension 244. E-mail: acooper@equitas.org

Vincenza Nazzari is the Director of Education at Equitas - International Centre for Human Rights Education. E-mail: vnazzari@equitas.org

Julie Kon Kam King is a Senior Program Officer at Equitas - International Centre for Human Rights Education. E-mail: jkonkamking@equitas.org

Annie Pettigrew is an Education Specialist at Equitas - International Centre for Human Rights Education. E-mail: apettigrew@equitas.org 
International Journal of Child, Youth and Family Studies (2013) 3.1: 489-501

Using Equitas’ Speaking Rights Program as a case study, this article attempts to provide insight into how human rights education (HRE) carried out according to a participatory approach contributes to youth empowerment which, in turn, leads to greater confidence and motivation among youth to participate in decisions that affect their lives.

The article begins by outlining the theoretical underpinnings of the curriculum design of the Speaking Rights Program and goes on to describe how the program is able to provide an enabling environment for youth empowerment aimed at the active participation of youth in their communities. The first section describes Equitas' participatory approach to HRE and the components of the Speaking Rights Program. It then explains how the approach is implemented in the program to foster empowerment and participation of youth. The second section offers areas for reflection, challenges encountered, and lessons learned since the program began.

It is important to note that all four authors have been closely involved in the design, development, and implementation of the Speaking Rights Program. As such, we have had the opportunity to monitor and evaluate the evolution of the program first-hand. Therefore our insights and learning captured below reflect the dual perspectives of participant and observer through which we experienced the Speaking Rights Program.

\section{Speaking Rights - An HRE Program}

For Equitas - International Centre for Human Rights Education ${ }^{1}$, HRE is a process of empowerment that begins with the individual and branches out to encompass society at large (Equitas, 2011). HRE includes all learning that builds knowledge and skills, as well as attitudes and behaviours that reflect the fundamental rights and freedoms articulated by the Universal Declaration of Human Rights, and that most importantly leads to action for social change (Delores, 1996; Equitas, 2011; United Nations, 2010). Ultimately, HRE inspires individuals to take control of their lives and become active participants in decisions that affect them. A participatory approach, grounded in transformative learning theory, is crucial to achieving the goal of empowerment. It is with this understanding of the potential of HRE that Equitas, in partnership with the City of Montréal, developed the Speaking Rights Program.

Speaking Rights is an HRE program that aims at developing the capacity of youth (12 to 18 years of age) to engage in actions that support respect for human rights. Young people participating in the Speaking Rights Program embark upon a process of empowerment guided by human rights values and principles. As they work through the program, they come to realize that their ideas and talents are key assets to society and that they have a responsibility to participate in building the kind of community in which they want to live. At the same time, youth workers

\footnotetext{
${ }^{1}$ Equitas - International Centre for Human Rights Education is a non-profit organization that advances equality, social justice, and respect for human dignity through innovative education programs in Canada and around the world. Equitas equips front line human rights defenders and educators, government institutions, and children and youth with knowledge, skills, and values to build a global culture of human rights. Equitas is based in Montréal, Canada.
} 
International Journal of Child, Youth and Family Studies (2013) 3.1: 489-501

involved in Speaking Rights become more aware of the real contribution youth can make to accomplish positive change in the community, as well as their own role as facilitators in this process (Equitas, 2012).

The components of the program include: the Speaking Rights toolkit, a facilitation tool for conducting HRE activities and projects with youth ${ }^{2}$; basic and advanced-level training for youth workers; follow-up coaching and support mechanisms for organizations; and financial and organizational support for youth-driven community action projects.

\section{The Participatory Approach in the Development of the Speaking Rights Program}

A participatory approach in HRE for youth promotes and values the sharing of personal knowledge and lived experience of human rights, and encourages critical reflection on individual beliefs and values. It is founded on principles of mutual respect and reciprocal learning and seeks out and includes the voice of the youth participants in all aspects of the learning process from the design and development to the implementation, evaluation, and follow-up. It enables youth with different backgrounds, cultures, values, and beliefs to work effectively together and learn from each other.

Speaking Rights starts from the premise that all youth, regardless of their situation, have something meaningful to contribute to society, and that it is important to enable each young person to develop the self-confidence and capability to participate. The participatory approach is critical to this youth-enabling process. It helps build in young people the necessary knowledge, confidence, self-esteem, and skills to first articulate their needs in human rights terms and then to undertake appropriate action to ensure that those rights are respected. It is an educational approach based on the belief that the purpose of education is to expand the ability of people including youth "to become shapers of their world by analyzing the social forces that have historically limited their options” (Nash, 2001, p. 188).

The participatory approach as implemented by Equitas consists of three fundamental characteristics or pillars. These are: starting with the participants' experience; critically analyzing and reflecting; and developing strategies for action (Equitas, 2011). These three conditions must be met both in the design and in the implementation of HRE. For Equitas, an important tool to help put the three pillars of the participatory approach into practice is the Learning Spiral model (Arnold, Burke, James, Martin, \& Thomas, 1991). The Learning Spiral (Figure 1) is the instructional design model that guides how the participatory approach is applied at various levels of the Speaking Rights Program.

\footnotetext{
${ }^{2}$ The Speaking Rights toolkit consists of 60 activities (including icebreakers and project ideas), plus detailed reference sheets for youth workers/facilitators that focus on building an understanding of human rights values and principles, as well as how to use the toolkit. The reference sheets highlight the various strategies youth workers can use to implement a participatory approach with their youth groups. They cover topics such as how to create open, safe, and democratic learning environments for youth, strategies for youth participation, in addition to information about the educational approach of the toolkit.
} 


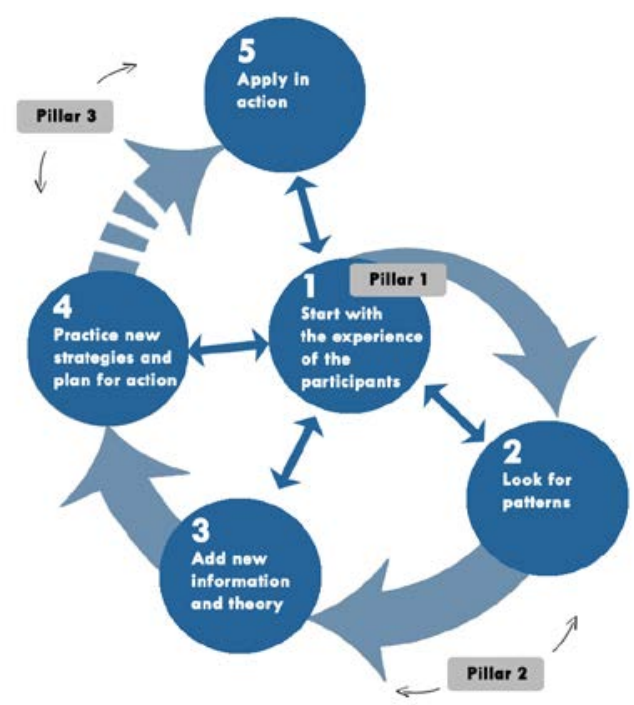

Figure 1. The Learning Spiral (Arnold et al., 1991).

Adapted with permission from the Doris Marshall Institute for Education and Action.

We describe how the three pillars of the participatory approach are applied in the Speaking Rights Program and how, through experiencing the approach, youth workers build their capacity to facilitate human rights education.

Pillar 1 - Starting with the experience of the participants. ${ }^{3}$ The Speaking Rights Program was developed in a manner in which the experiences of youth, youth workers, and youth-serving community-based organizations were central to the design, development, implementation, and continuous evaluation of the program. A needs assessment, designed to ensure that all stakeholders would have an equal opportunity to participate and contribute their expertise in shaping the direction of the program was carried out with more than 280 youth, youth workers, and youth-serving community-based organizations in Montréal, Vancouver, Surrey, Victoria, and Winnipeg ${ }^{4}$. A common characteristic among the young people surveyed was that they had rarely, if ever, had the opportunity to actively participate in their community organization, their school, or broader community, and in some cases even in their own families. This made clear the appropriateness of a participatory approach that values participants' knowledge and capacity and provides a safe and collective space for sharing and analyzing personal experiences.

The ongoing evaluation process of the program has enabled Equitas to draw on the evolving experience of stakeholders. It has allowed us to expand or adapt the program to address their changing needs and interests. As a result of their feedback, a number of elements have been

\footnotetext{
${ }^{3}$ Pillar 1 corresponds to the first step of the Learning Spiral model: start with the experience of participants.

${ }^{4}$ The program was first developed in Montréal and has since expanded to include Vancouver, Surrey, Chilliwack, Lillooet, Victoria, Winnipeg, Toronto, and Kahnawà:ke.
} 
International Journal of Child, Youth and Family Studies (2013) 3.1: 489-501

added to the Speaking Rights Program including 12 new activities, two new reference sheets, one additional community action project, and two specialized training programs for youth workers on the topic of youth participation. What's more, a working group representing 20 different youth organizations continues to meet biannually in Montréal and Vancouver to provide feedback to Equitas on the Speaking Rights Program and to help define the strategic direction moving forward.

Different stakeholders have consistently reported that their active involvement in shaping the direction of the Speaking Rights Program has been both a motivating and empowering experience. Drawing on their day-to-day practice, they feel they can continue to contribute to enriching the program through their suggestions, comments, and actions.

The design of the Speaking Rights toolkit activities ${ }^{5}$ is such that they provide a framework for dialogue and exploration, where much of the content comes from the participating youth. These types of activities enable youth to make conscious or unconscious connections with prior experiences or familiar situations which, as a result, become new and meaningful experiences on which they can base their thinking (Taylor, 1998). Through the toolkit activities, youth share personal stories, facts, or opinions that they might not otherwise recount. They get to know each other better, their self-confidence increases, and they become aware that their experiences, feelings, and thoughts are important and worth revealing to others. As one youth worker described:

Taking a position is new and difficult [for youth]. At school there is always a right answer and a wrong answer, but in these activities, it is their own answer that matters. [By sharing their opinion by] taking a physical place on the line, they are able to build the skills to take a position on something.

Pillar 2 - Critically analyzing and reflecting. ${ }^{6}$ Building the understanding and capacity of youth workers to lead a process of critical reflection with their youth and develop opportunities for "transformation" ${ }^{7}$ is fundamental to the success of the participatory approach and central to the design of Speaking Rights.

During their training, youth workers are exposed to approximately one-quarter of the activities in the Speaking Rights toolkit. As participants in the activities, they are also exposed to a transformative learning opportunity as they are asked to confront their own biases and prejudices, and come to understand how their personal world view influences their judgment and behaviour. Drawing on this transformative experience, they consider the potential effect, both positive and negative, a specific activity may have on participating youth and are encouraged to

${ }^{5}$ An example of how a Speaking Rights activity was designed according to the Learning Spiral is provided in the appendix.

${ }^{6}$ Pillar 2 corresponds to steps two and three of the Learning Spiral model: look for patterns (step 2 ) and add new information and theory (step 3).

${ }^{7}$ Critical reflection is central to the transformative learning process described by Mezirow (1990). Transformative learning opportunities that encourage critical reflection lead to the reevaluation of underlying assumptions, perspectives, and world views (Taylor, 1998). 
share strategies to ensure its appropriateness for their youth groups. This process not only contributes to their own critical reflection, but also to ensuring the safety and well-being of their youth (Dworkin \& Larson, 2006; Fraser-Thomas \& Côté, 2009).

In debriefing toolkit activities, youth workers need to be able to encourage youth to discuss their experiences and surface patterns or ideas that are shared with others. Through a process of guided discourse during which a diversity of views emerge, youth are able to critically examine their own assumptions, test their own justifications, and make decisions based upon the resulting consensus (Taylor, 1998). Mezirow (1990) suggests that the most significant learning occurs through articulating with others one's values, beliefs, and feelings. Through the debrief discussions, youth contribute new knowledge or ideas, further building mutual awareness and experience. The debrief scaffolds the critical reflection process and supports empowerment by encouraging youth to think about what happened during the activity and to draw life lessons that they can apply in other contexts. It gives youth the opportunity to discover the importance of human rights values for themselves and encourages them to suggest ways to actually live in line with these values. It also encourages the full participation of youth by giving them the opportunity to exercise their right to express themselves and be heard.

The Speaking Rights training requires youth workers to think critically about their role as facilitators and their responsibility to create an environment where young people feel safe and secure. They also build their understanding of the human rights framework as a tool for analyzing their contexts and enabling the youth they work with to do the same. Research shows that youth workers who are trained and well equipped with skills and resources to openly address issues that are foremost on the minds of youth, and who can act as role models, can be critical in helping youth as they develop the skills that can help shape their future (Eccles \& Gootman, 2002). Youth workers involved in the Speaking Rights Program, must, at a minimum, participate in a one-day training session about the program and its underlying approach. Training plays a significant role in strengthening the capacity of youth workers to engage in a process of critical reflection with their youth and in ensuring the success of the program. For these reasons, Equitas made a conscious decision not to do a mass distribution of the Speaking Rights toolkit without the benefit of training for the youth workers.

Pillar 3 - Developing strategies for action. ${ }^{8}$ Critical reflection in itself is not sufficient for empowerment and transformation. Freire (1970) believed that this reflection must also result in concrete action. From his perspective, true transformation implies that learners change their behaviours to transform their reality, and transform society as a whole. The Speaking Rights Program guides youth and youth workers through a process for developing concrete actions that will contribute to change in their communities. Through training, follow up and community action projects, youth and youth workers are able to practise new skills and apply their learning in action. The literature supports the importance of practising new skills in order to ensure the effectiveness of programs that aim to develop prosocial behaviours among youth (Durlak, Weissberg, \& Pachan, 2010).

\footnotetext{
${ }^{8}$ Pillar 3 corresponds to steps four and five of the Learning Spiral model: practise new strategies
} and plan for action (step 4) and apply in action (step 5). 
During the training, youth workers spend time with their colleagues developing action plans for putting their learning into practice, with the aim of increasing their organization's capacity to conduct HRE through a participatory approach. The program supports youth in the development and implementation of community action projects to address issues that are important to them, that make connections with human rights values, and that incorporate a participatory approach. ${ }^{9}$ Examples of community action projects undertaken by youth groups to date include: (a) art-based initiatives to promote gender equality, respect for diversity, and human rights values within local communities; (b) youth-led public events to raise awareness about poverty, discrimination, and social exclusion; and (c) youth-led forums to discuss and find ways to reduce cyber-bullying, homophobia, and racism (see Figure 2 for more detailed examples).

\section{Figure 2. Examples of Speaking Rights community action projects.}

Rights on the Street! YWCA, Montréal, Quebec

A group of 10 girls raised awareness about human rights values through a community art event in the streets of downtown Montréal. Through painting, they invited neighbours, partners, and people on the street to express themselves about human rights values. They distributed free food thanks to donations they received to support their project. More than 250 people attended the activity.

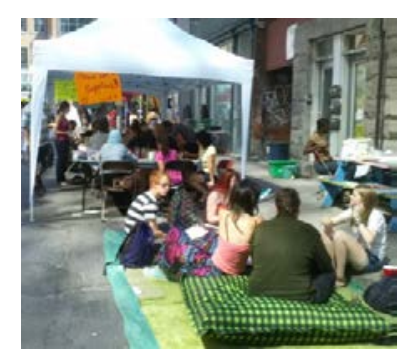

Write4Rights Ann Davis Transition Society, Chilliwack, British Columbia

A group of youth created a graffiti wall within their school which promotes positive human rights values. They spoke to their peers about the importance of respect and human rights, and with the support of their teachers and principal, they created a rights awareness campaign in their school.

\section{What Makes You Beautiful? Dawson Community Centre, Montréal}

This project brought together eight girls who photographed women from their communities asking them: What makes you beautiful? The girls asked the women to link their personal definition of beauty to human rights values. Photographs were mounted on a giant canvas and presented at the Dawson Community Centre’s Annual General Meeting. They are now permanently exhibited at the centre.

${ }^{9}$ To ensure that the community action projects developed by youth workers with their youth can actually be implemented, the Speaking Rights Program provides materials and financial resources to support organizations in this endeavour. Through a mini-grants process, youth groups are eligible for up to $\$ 500$ for materials and other resources needed for their projects. Furthermore, Equitas provides ongoing coaching to the youth workers ranging from how to write a proposal for grants and develop budgets all the way to celebrating the successes of the initiatives undertaken. 
International Journal of Child, Youth and Family Studies (2013) 3.1: 489-501

Youniss, McClellan, and Yates (1997) assert that the impact of these types of initiatives are far reaching, helping to engender civic identity into adulthood: "By offering youth meaningful participatory experiences, we allow them to discover their potency, assess their responsibility, acquire a sense of political processes, and commit to a more ethical ideology" (p. $629)$.

It is interesting to note that during follow-up interviews, a number of youth workers conceded that their own programming would probably not change the reality facing youth. Significantly altering the environment of violence, emotional neglect, or discrimination rampant in their communities is well beyond their scope of influence. However, youth workers do feel that with continued involvement in the Speaking Rights Program, they are in a position to change how youth perceive their realities, moving toward a way of looking at life that is more positive and hopeful. As one youth worker explains:

Our objective isn't for the youth to remember every detail, but to have them think and be critical about what they are seeing and experiencing. Often they are the victims of racism and so they react negatively in a way that reinforces those that oppress them. For example, they are aggressive toward the police or obnoxious in stores.... But through the discussions after the activities, they've been able to realize that they should not aggravate the problem and add to it, but defuse the violence instead.

\section{Sustainability of the Speaking Rights Program - Challenges and Lessons Learned}

Since the official launch of Equitas' Speaking Rights Program in 2010, 200 community organizations and 450 youth workers in Montréal, Vancouver, Surrey, Chilliwack, Lillooet, Victoria, Winnipeg, Toronto, and Kahnawà:ke have joined together to promote youth voices and leadership in their communities. Through the use of program activities and projects they have supported the positive engagement of over 5,500 youth. As noted earlier, continuous engagement with a majority of Speaking Rights stakeholders has allowed the program to develop content and direction that reflect the needs and interests of those involved. As with most programs like Speaking Rights, however, a major challenge is ensuring sustainability. The longer-term success of a program such as Speaking Rights depends to a significant degree on its adoption and continued use by its stakeholders. We offer our reflections and some strategies that can contribute to supporting sustainability.

\section{Engaging Youth Workers in the Speaking Rights Approach}

The Speaking Rights approach places youth workers in the role of facilitator and this is relatively new and challenging for many of them. Some youth workers have reported that they are at times reticent or apprehensive to try activities that involve subject areas in which they lack familiarity, such as racism, sexuality, and youth rights. Engaging youth around these issues requires experience on the part of youth workers in navigating differing opinions and addressing sometimes challenging questions from youth. Many of the youth workers recognize the value and importance of not just informing youth about issues, but also providing safe spaces to discuss them with youth. Although youth workers report they are better able to support youth 
International Journal of Child, Youth and Family Studies (2013) 3.1: 489-501

empowerment and participation through youth-led initiatives and community action projects, they acknowledge that they need more skills. Regular follow-up training, coaching, and on-site visits are incorporated into the Speaking Rights Program to support youth workers in their own learning about the approach and about human rights. Moving forward, it is important to consider how the program can provide more proactive, continuous, and flexible means to support youth workers as they develop their capacity to facilitate human rights education and integrate the participatory approach into their work.

Going beyond training and support. For there to be intentional, planned, and systematic use of the Speaking Rights Program, both management and staff need to see the connection between the goals and values of the program and what they as an organization are trying to achieve with respect to youth empowerment and participation. Equitas' experience, both in Canada and internationally, has shown it is important to go beyond training and support for youth workers and ensure organizational buy-in at the supervisory level for a program and its underlying approach. Notably, Equitas’ work with Play it Fair! (a program similar to Speaking Rights but geared toward children 6 to 12 years old) has indicated that adoption and acceptance at the management level is critical to firmly establish a program within an organization and make sure that the values and approach of the program remain a priority from year to year. Such buy-in helps support day-to-day use of the program and ensures that there are enough resources allocated to it. In addition, Equitas has learned that uptake of programs such as Speaking Rights will not be successful unless there is alignment with a partner organization's own values or mission.

Developing the organizational culture. An organizational culture that places a high priority on youth empowerment and participation and reflects the values of human rights within youth-serving organizations is a key factor in supporting sustainability. Developing this culture, however, requires experienced staff as well as adequate time and resources. The reality of these organizations is that there is high staff turnover and very often lack of time and resources to effectively plan and develop long-term programming. Training more than one person at a time from each partner organization engaged in the program contributes greatly to stronger support and motivation for the program within the organization. Garnering enthusiastic organizational participation will also go a long way in encouraging and supporting the necessary new behaviours that are essential to altering culture.

Engaging the broader community. Meaningful youth participation and empowerment occurs in partnership with adults across the wider community (Cook, Blanchet-Cohen, \& Hart, 2004). Both youth and youth workers have reported that their participation in Speaking Rights community action projects have led to positive changes. Through concrete actions such as art exhibits, graffiti walls, youth councils, and other initiatives they have developed their skills and sense of agency in the community. While these action projects reflect an important step in building empowerment and participation of the youth involved, Equitas recognizes the need to capitalize on this momentum and expand these initiatives so that they not only impact youth organizations, but also contribute to substantive change within a particular community. As Hughes \& Curran (2000) explain, genuine youth participation must look beyond having a program for youth and toward a more holistic view of a community where we don't "work on young people” but “work with young people.” In many cases youth-serving organizations remain 
International Journal of Child, Youth and Family Studies (2013) 3.1: 489-501

on the exterior or periphery of community development initiatives (Tolman \& Pittman, 2001), so it is important that Equitas reflect on how to overcome these barriers.

\section{Conclusion: Making the Change We Want to See}

Youth voices, especially those marginalized by society, are rarely listened to and consulted by the community at large (Burgess, 2000; Curran, Bowness, \& Comack, 2010). The program's current focus on youth and youth workers in community-based organizations therefore may be limiting the full potential of meaningful youth participation. To increase effectiveness, it is important to envision a program that integrates a "whole community approach” and addresses community change and growth (Warner, Langlois, \& Dumond, 2010). Consequently, to create the necessary social conditions for youth empowerment across a community, Equitas will need to expand partnerships beyond youth-serving organizations to include other community actors such as parents, teachers, and decision-makers.

The Speaking Rights Program is currently being implemented in nine cities and in just over 200 organizations across Canada. Equitas is in the process of identifying ways to provide necessary follow-up and coaching while at the same time trying to balance this with an increasing demand from new youth organizations that want to participate in the program. It is becoming evident that Equitas has to make some strategic decisions regarding whether to focus on depth or breadth of scope in the evolution of the Speaking Rights Program.

For many participating youth, engaging in Speaking Rights has provided the first opportunity to participate and express themselves on issues that matter to them. As a result, youth are coming back to their youth centres wanting to discuss, learn, and take action. An individual's decision to feel, think, or act differently is a foundational step toward transformation. In partnership with their youth workers, youth are making some initial links with their local communities in an effort to contribute to social change. It is clear that the essential practices and conditions of a participatory approach to HRE, such as those integrated throughout the Speaking Rights Program, have tremendous potential to support the development of strong and healthy democratic communities. Continuing to work together, while challenging both ourselves and our partners to critically reflect on how best to make the change we want to see, will surely engender youth empowerment and greater participation.

I've seen these girls changing: from the disinterest climate at the beginning came a lively atmosphere of solidarity and collaboration. They learned how to create a project, master entrepreneurship skills and techniques, take some responsibilities, become engaged, and invest their leadership in a common cause not just their individual interest. Furthermore they are interested in coming back to the Action Council next year to do new community projects! (Youth coordinator, personal communication, 2012) 
International Journal of Child, Youth and Family Studies (2013) 3.1: 489-501

\section{References}

Arnold, B., Burke, B., James, C., Martin, D., \& Thomas, B. (1991). Educating for a change. Toronto: Between the Lines.

Burgess, J. (2000). Youth involvement can be the key to community development. Community Youth Development Journal, 1, 38-41. Retrieved from https://plus28.safeorder.net/cydjournal/2000Winter/burgess.html

Cook, P., Blanchet-Cohen, N., \& Hart, S. (2004). Children as partners: Child participation promoting social change. Victoria, BC: International Institute for Child Rights and Development. Retrieved from http://resourcecentre.savethechildren.se/content/library/documents/children-partnerschild-participation-promoting-social-change

Curran, A., Bowness, E., \& Comack, C. (2010). Meeting the needs of youth: Perspectives from youth-serving agencies. Ottawa: Canadian Centre for Policy Alternatives. Retrieved from http://www.polic yalternatives.org/publications/reports/meeting-needs-youth

Delores, J. (1996). Education: The necessary utopia. In UNESCO, Learning: The treasure within (pp. 13-35). Paris, France: United Nations Educational, Scientific and Cultural Organization.

Durlak, J. A., Weissberg, R. P., \& Pachan, M. (2010). A Meta-analysis of after-school programs that seek to promote personal and social skills in children and adolescents. American Journal of Community Psychology, 45(3/4), 294-309. doi: 10.1007/s10464-010-9300-6

Dworkin, J., \& Larson, R. (2006). Adolescents’ negative experiences in organized youth activities. Journal of Youth Development: Bridging Research and Practice, 1(3), 1-19.

Eccles, J. S., \& Gootman, J. A. (2002). Community programs to promote youth development. Washington, DC: National Academies Press.

Equitas - International Centre for Human Rights Education \& Office of the United Nations High Commissioner for Human Rights. (2011). Evaluating human rights training activities. A handbook for human rights educators. Geneva, Switzerland: Office of the United Nations High Commissioner for Human Rights.

Equitas - International Centre for Human Rights Education. (2012). Speaking rights: Human rights education toolkit for youth - 12 to 18. Montréal: Author.

Fraser-Thomas, J., \& Côté, J. (2009). Understanding adolescents’ positive and negative developmental experiences in sport. The Sport Psychologist, 23, 3-23.

Freire, P. (1970). Pedagogy of the oppressed. New York: Herder and Herder. 
International Journal of Child, Youth and Family Studies (2013) 3.1: 489-501

Hughes, D. M., \& Curran, S. P. (2000). Community youth development: A framework for action. Community Youth Development Journal, 1, 7-13. Retrieved from https://plus28.safeorder.net/cydjournal/2000Winter/hughes.html

Mezirow, J. (1990). Fostering critical reflection in adulthood: A guide to transformative and emancipatory learning. San Francisco, CA: Jossey-Bass.

Nash, A. (2001). Participatory workplace education: Resisting fear-driven models. In P. Campbell \& B. Burnaby (Eds.), Participatory practices in adult education (pp. 185-196). Mahwah, NJ: Lawrence Erlbaum.

Taylor, E. W. (1998). The theory and practice of transformative learning: A critical review. Columbus, OH: ERIC Clearing House. Retrieved from http://www.calproonline.org/eric/docs/taylor/taylor_00.pdf

Tolman, J., \& Pittman, K. (2001). Youth acts, community impacts: Stories of youth engagement with real results. The Community and Youth Development Series, 7. Takoma Park, MD: The Forum for Youth Investment, International Youth Foundation.

United Nations. (2010). World program for human rights education: Plan of action - Second phase. Geneva: Office of the High Commissioner for Human Rights. Retrieved from http://www.ohchr.org/Documents/Publications/WPHRE_Phase_2_en.pdf

Warner, A., Langlois, M., \& Dumond, C. (2010). Voices from youth action teams: Creating successful partnerships for community action. In W. Linds, L. Goulet, \& A. Sammel (Eds.), Emanicipatory practices: Adult/youth engagement for social and environmental justice (pp. 95-108). Rotterdam, The Netherlands: Sense Publishers.

Youniss, J., McClellan, J. A., \& Yates, M. (1997). What we know about engendering civic identity. The American Behavioral Scientist, 40(5), 620-631. 
International Journal of Child, Youth and Family Studies (2013) 3.1: 489-501

\section{Appendix}

\section{Steps of the Learning Spiral Model: Toolkit Activity 6 - One Step Forward}

In this role-play activity, participants put themselves in someone else's shoes and try to imagine what their life is like. Participants are given a role card specifying an identity, for example: You are 15 years old. You are a lesbian; or Your parents are rich; or You are 14 and your parents don't let you go out after 8:00 p.m. Based on the identity, participants build their image of the person. The facilitator then reads a series of statements such as: You have never been in serious financial difficulty; or You have never been discriminated against; or You can fall in love with whomever you choose. If the participants think the statement applies to the role on their card, they take a step forward. If not, they must stay where they are. Once all the statements have been read out, some participants will find themselves at the front of the room, while others will not have moved at all. The facilitator then asks participants in turn to reveal their identity to the group and then leads a debrief using the feel, think, and act questions provided.

\begin{tabular}{|c|c|}
\hline $\begin{array}{l}\text { Step 1: Start with } \\
\text { experience of } \\
\text { participants }\end{array}$ & $\begin{array}{l}\text { The activity begins by asking participants to imagine their roles. The roles are } \\
\text { intentionally vague so that participants develop an identity for their characters based } \\
\text { on their own experiences and which consequently will very likely reflect their biases } \\
\text { and preconceptions. Drawing on their experiences of what it means for example to be } \\
\text { rich or to be a lesbian, participants take a step forward or stay where they are. }\end{array}$ \\
\hline $\begin{array}{l}\text { Step 2: Look for } \\
\text { patterns }\end{array}$ & $\begin{array}{l}\text { During the debrief, the facilitator asks participants to identify how they felt being } \\
\text { able to move forward or when they couldn’t (feel questions) as well as lessons they } \\
\text { have drawn from the experience (think questions). Through the discussion, youth } \\
\text { recognize that various opportunities in life are mediated by not only their financial or } \\
\text { social standing, but also by personal characteristics such as sense of self-worth. }\end{array}$ \\
\hline $\begin{array}{l}\text { Step 3: Add new } \\
\text { information }\end{array}$ & $\begin{array}{l}\text { The debrief is also an opportunity to hear from others in the group and add new } \\
\text { perspectives to a given role (think questions). This is particularly effective when two } \\
\text { or more participants are provided with the same role but end up in different parts of } \\
\text { the room. The exchange between them provides a platform to explore how our } \\
\text { experiences and world view can affect our standing in life. }\end{array}$ \\
\hline $\begin{array}{l}\text { Step 4: Put } \\
\text { learning into } \\
\text { practise }\end{array}$ & $\begin{array}{l}\text { The debrief may bring to the surface issues of discrimination and exclusion, } \\
\text { opportunities for marginalized youth in the community, or factors that promote } \\
\text { agency and participation. The last series of questions during the debrief (act } \\
\text { questions) ask participants to reflect on the issues at hand, identify what kind of } \\
\text { changes are possible and their role in the process. }\end{array}$ \\
\hline $\begin{array}{l}\text { Step 5: Apply } \\
\text { learning in action }\end{array}$ & $\begin{array}{l}\text { The activity provides the catalyst and platform for encouraging youth and youth } \\
\text { workers to apply their learning in action. Continued support from youth workers and } \\
\text { youth peers is necessary to integrate the lessons learned into observable behaviours } \\
\text { or changes within the group. }\end{array}$ \\
\hline
\end{tabular}

